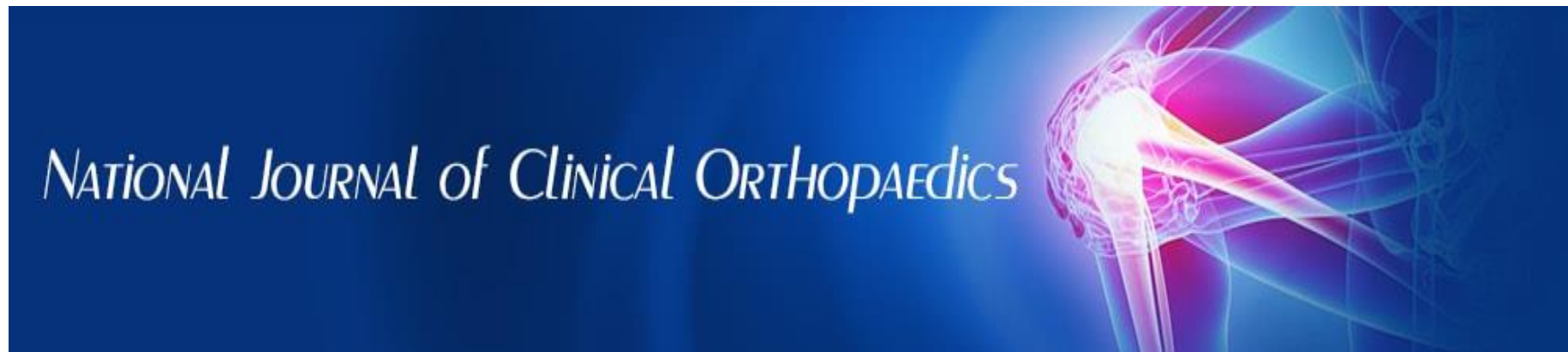

ISSN (P): 2521-3466

ISSN (E): 2521-3474

(C) Clinical Orthopaedics www.orthoresearchjournal.com 2021; 5(3): 177-180

Received: 22-05-2021

Accepted: 24-06-2021

\section{Dr. Gaurav M}

Assistant Professor, Department of Orthopaedics, Bangalore Medical College and Research Institute Bangalore, Karnataka, India

\section{Dr. Chethan BA}

Senior Resident, Department of Orthopaedics, Shri Atal Bihari Vajpayee Medical College and Research Institute Bangalore, Karnataka, India
Corresponding Author: Dr. Chethan BA

Senior Resident, Department of Orthopaedics, Shri Atal Bihari Vajpayee Medical College and Research Institute Bangalore, Karnataka, India

\section{Impact of location of disc relative to root - Axillary Vs shoulder on functional outcome in patients with lumbar disc herniation following micro-discectomy}

\author{
Dr. Gaurav M and Dr. Chethan BA
}

DOI: https://doi.org/10.33545/orthor.2021.v5.i3c.338

\section{Abstract}

The purpose of this study was to evaluate the functional outcome following surgery in axillary versus shoulder type of disc herniation.

Patients who presented to Victoria \& Bowring hospitals with disc herniation were divided into two groups, Shoulder and Axillary group of disc herniation. All the patients in study underwent discectomy. The study period spanned from February 2017 to July 2018 with the sample size of 116 patients.

They were followed for a minimum of 12 months.

Functional outcome was measured using Oswestry Disability Index score. The patient global outcomes were categorized based on the Modified Macnab criteria.

The mean ODI improved significantly from $66.58 \%$ to $14.00 \%$ in the axillary disc group and from $63.59 \%$ to $13.88 \%$ in the shoulder disc group $(p<0.05)$. And the final outcome was found to be Excellent or good in 56 of the 64 patients in the shoulder disc group and in 46 of the 52 patients in the axillary disc group. Though we did not find any significant difference in the functional outcome, knowledge of the functional outcome following discectomy in shoulder vs axillary disc herniation, helps the spine surgeon provide patients information for an effective decision making.

Keywords: Oswestry disability, shoulder, axillary

\section{Introduction}

Lumbar disc herniation is the most common diagnosis among the degenerative abnormalities of the lumbar spine (affecting 2 to $3 \%$ of the population), and is the principal cause of spinal surgery among the adult population. Non-operative treatment is the mainstay of initial management of LDH. More than $90 \%$ of patients will improve with conservative care, and surgery is rarely indicated before six weeks after onset of symptoms in the absence of cauda equine syndrome ${ }^{[1]}$. Lumbar discectomy is the most commonly performed spine surgery in patients with failed conservative treatment ${ }^{[2,3]}$.

Two types of disc herniation can be described according to the direction of herniated disc material: shoulder type and axillary type. Axillary disc herniation is described when the extruded disc fragment lies in the recess between the lateral border of cauda equina and medial to the nerve roots, while in the shoulder type the disc lies lateral to the nerve roots.

\section{Aims and Objectives}

The purpose of this study was to evaluate the functional outcome following surgery in axillary versus shoulder type of disc herniation.

\section{Methodology}

Patients who presented to Victoria \& Bowring hospitals between February 2017 to July 2018, with lumbar disc herniation who required primary operative intervention with conventional open lumbar discectomy after a course of conservative treatment were studied. Based on the pre-operative MRI and intraoperative finding, the patients were divided into two groups: one with an axillary disc herniation and the other with shoulder disc herniation. All patients underwent discectomy.

The patients were followed up in outpatient setup for a minimum of 12 months. 
Lower limb pain was assessed using VAS score. Functional outcome was measured using Oswestry Disability Index score. The patient global outcomes were categorized as excellent, good, fair, and poor based on the Modified Macnab criteria ${ }^{[4,5]}$ at the final follow-up. Perioperative data such as operative time, hospital stay, and time to return to work were evaluated. Return to work was defined as resuming work tasks/work hours after a period of sick leave ${ }^{[6,7]}$. Surgical complications and recurrence were also documented.

\section{Surgical technique}

The conventional open lumbar discectomy was performed via posterior interlaminar or translaminar access. The operation started with a 1-inch long skin incision under general anesthesia. A microscope-assisted lumbar laminotomy was then performed. Ligamentum flavum was resected followed by exposure of the epidural space and herniated disc compressing the neural tissues. The herniated disc can be removed with careful nerve root dissection and retraction. The operation was finished with complete hemostasis and standard wound closure.

\section{Observation and Results}

A total of 116 patients met the inclusion criteria. The mean age of patients was 34.9 years (range 19-45 years). Mean follow up was 1.29 years (range 12 months - 2 years). The incidence of axillary disc was $44.8 \%$ (52 cases) and shoulder disc was $55.2 \%$ (64 cases) among the operated cases.

Table 1: Age group

\begin{tabular}{|c|c|}
\hline Age group & $19 \mathrm{yrs}-45 \mathrm{yrs}$ \\
\hline Follow-up & $9 \mathrm{mon}-2 \mathrm{yrs}$ \\
\hline
\end{tabular}

Table 2: Mean Age

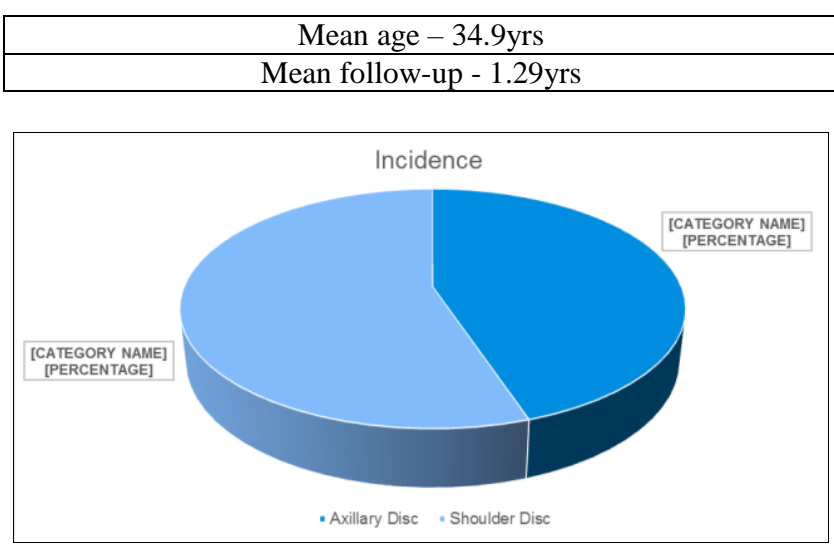

Fig 1: Incidence

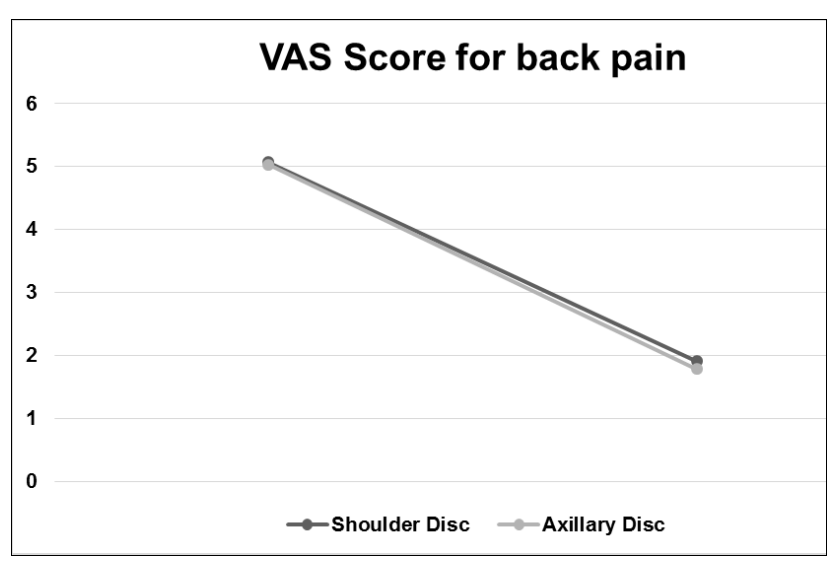

Fig 2: VAS Score for back pain
The mean ( \pm standard deviation) VAS score for back pain improved from $5.06 \pm 2.00$ to $1.90 \pm 1.01$ in the shoulder disc group and from $5.02 \pm 1.83$ to $1.77 \pm 0.76$ in the axillary disc group.

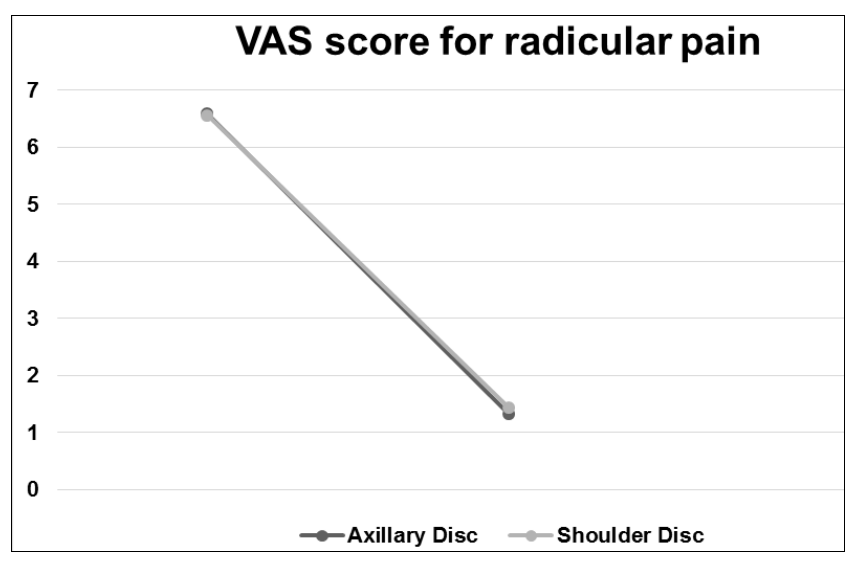

Fig 3: VAS Score for radicular pain

The mean VAS score for radicular pain improved from $6.55 \pm$ 2.31 to $1.43 \pm 1.02$ in the shoulder disc group and from $6.58 \pm$ 1.77 to $1.32 \pm 1.02$ in the axillary disc group.

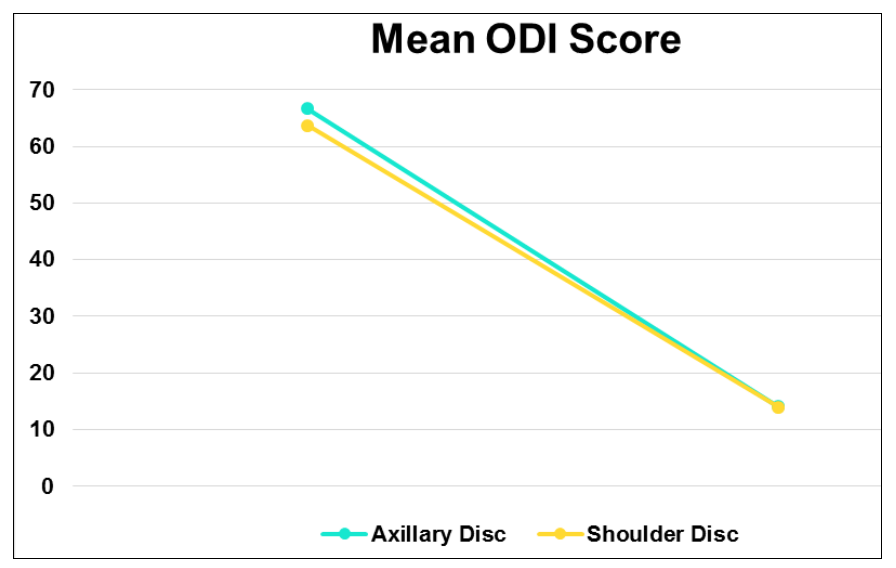

Fig 4: Mean ODI Score

The mean ODI improved significantly from $66.58 \% \pm 15.78 \%$ to $14.00 \% \pm 11.06 \%$ in the axillary disc group and from $63.59 \% \pm$ $15.57 \%$ to $13.88 \% \pm 12.16 \%$ in the shoulder disc group $(\mathrm{p}<0.05)$. 1 patient with axillary disc herniation had dural tear during surgery which was repaired. However, he reported good outcome at 1 year follow up.

1 patient in shoulder disc herniation group developed symptomatic reherniation which required surgery at 6 months follow up. Based on the Modified Macnab Criteria, the final outcome was found to be excellent or good in 56 of the 64 patients $(87.5 \%)$ in the shoulder disc group and in 46 of the 52 patients $(88.46 \%)$ in the axillary disc group.

Table 3: Modified Macnab Criteria

\begin{tabular}{|c|c|}
\hline Outcome & Characteristics \\
\hline Excellent & $\begin{array}{c}\text { No pain, no restriction of mobility, Return to normal work } \\
\text { and level of activity }\end{array}$ \\
\hline Good & $\begin{array}{c}\text { Occasional non radicular pain, Relief of presenting } \\
\text { symptoms, Able to return to modified work }\end{array}$ \\
\hline Fair & $\begin{array}{c}\text { Some improved functional capacity, Still handicapped } \\
\text { and/or unemployed }\end{array}$ \\
\hline poor & $\begin{array}{c}\text { Continued objective symptoms of root involvement, } \\
\text { Additional operative intervention needed at index level } \\
\text { irrespective of length of postoperative follow-up }\end{array}$ \\
\hline
\end{tabular}




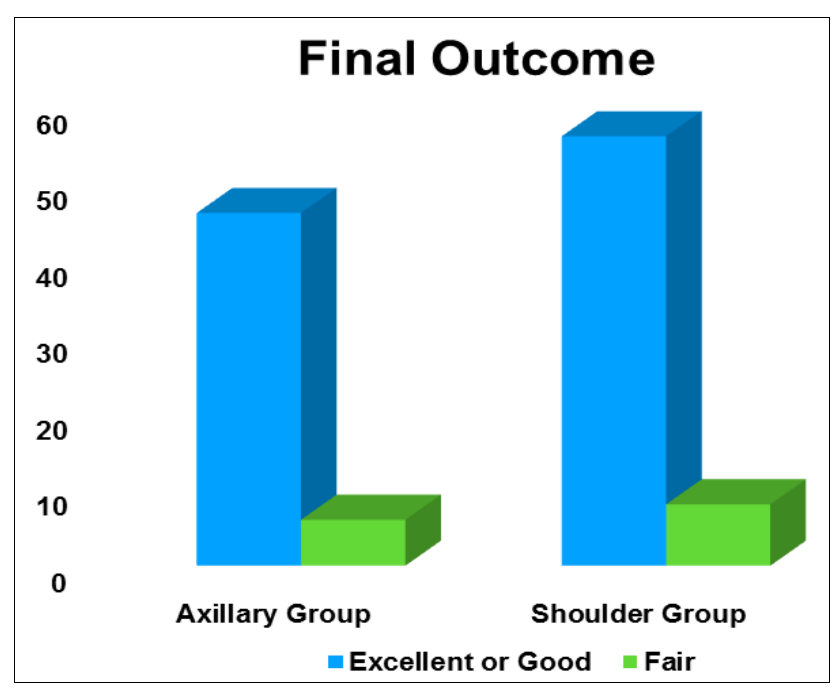

Fig 6: Final outcome

\section{Discussion}

Axillary disc herniation is a type of disc extrusion, which affects both exiting and descending nerve roots. The extruded material travels posteriorly into the axilla between the nerve roots laterally and thecal sac medially ${ }^{[8]}$. In shoulder type of disc extrusion, the extruded disc material lie lateral or ventral to nerve root on axial images. As the surgical approach to the disc herniation is different according to the direction of the disc material, nomenclature and the identification of this disc herniation is utmost important $[9,8,10]$.

Due to the relative difficulty in handling the axillary disc herniation while removing the disc material there is a theoretical increased risk of complication during surgery.

An axillary type of disc herniation is a common cause of incomplete removal of herniated disc material in cases of percutaneous endoscopic lumbar discectomy. Remaining herniated disc fragments located in the epidural space compressing the traversing nerve root have been found [11] However in our cases done via conventional open micro discectomy, we did not find much difficulty removing all the fragments.

Shriver et al. found overall complication rates of $12.5 \%, 13.3 \%$, and $10.8 \%$ for open microdiscectomy, micro-endoscopic discectomy (MED), and percutaneous micro-discectomy respectively in their analysis of 42 studies ${ }^{[9]}$.

The purpose of our study was to find out if any difference is there in the functional outcome following surgery for axillary and shoulder disc herniation.

In our study we did not find any significant difference in the functional outcome between the two groups.

Table 4: Oswestry Disability Index

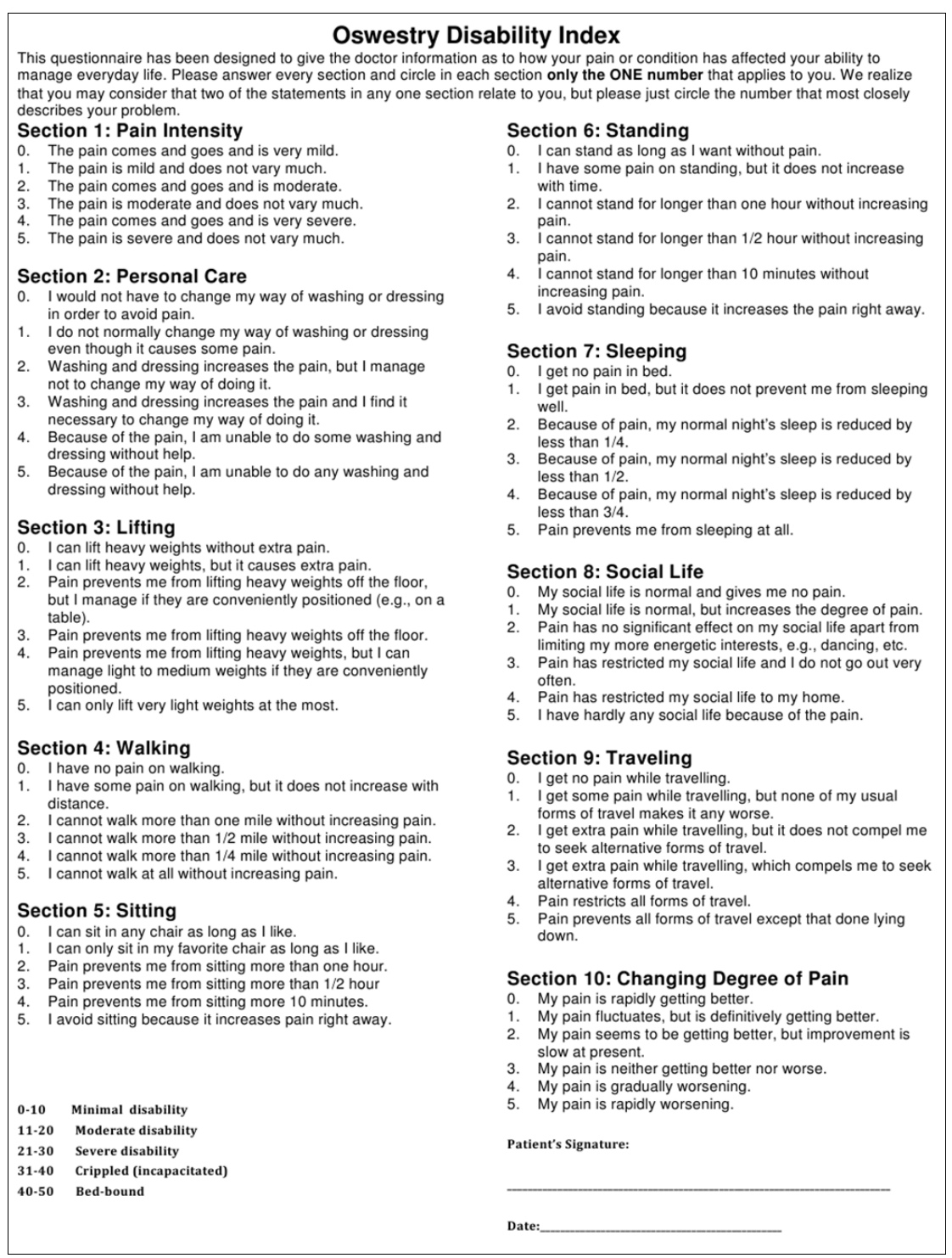


Table 5: Assessment of Oswestry Disability Index (ODI)

\begin{tabular}{|c|c|}
\hline Score & Interpretation \\
\hline $0-20 \%$ & Minimal Disability: Can cope with most daily activities \\
\hline $21-40 \%$ & Moderate Disability: Pain and difficulty with sitting, lifting and standing. The patient may be disabled from work \\
\hline $41-60 \%$ & Severe Disability: Pain is the main problem, but other areas are affected \\
\hline $61-80 \%$ & Crippled: Back pain impinges on all aspects of the patient's life \\
\hline $81-100 \%$ & These patients are either bed-bound or else exaggerating their symptoms \\
\hline
\end{tabular}

\section{Conclusion}

Lumbar discectomy for LDH is an established and effective treatment for symptomatic patient that have failed conservative treatment. With knowledge of the functional outcome following discectomy in shoulder vs axillary disc herniation, the spine surgeon can provide patients information for an effective decision making. In our study we did not find any significant difference in the functional outcome.

\section{References}

1. McCulloch JA. Focus issue on lumbar disc herniation: macro and microdiscectomy. Spine. 1996;21(24 Suppl):45S-56S.

2. Gray DT, Deyo RA, Kreuter W, Mirza SK, Heagerty PJ, Comstock BA. Population-based trends in volumes and rates of ambulatory lumbar spine surgery. Spine. 2006;31(17):1957-1963. discussion 1964. https://doi.org/10.1097/01.brs.0000229148.63418.c1

3. Best NM, Sasso RC. Success and safety in outpatient microlumbar discectomy. J Spinal Disord Tech. 2006;19(5):334-337. https://doi.org/10.1097/01.bsd.0000210119.47387.44

4. Yeung AT, Tsou PM. Posterolateral endoscopic excision for lumbar disc herniation: Surgical technique, out come, and complications in 307 consecutive cases. Spine (Phila $\mathrm{Pa}$ 1976). 2002;27:722-731.

5. Macnab I. Negative disc exploration. An analysis of the causes of nerve-root involvement in sixty-eight patients. J Bone Joint Surg Am. 1971;53:891-903.

6. Hees HL, Nieuwenhuijsen K, Koeter MW, Bültmann U, Schene AH. Towards a new definition of return-to-work out-comes in common mental disorders from a multistakeholder perspective. PLoS One. 2012;7:e39947.

7. Steenstra IA, Lee H, de Vroome EM, Busse JW, HoggJohnson SJ. Comparing current definitions of return to work: A measurement approach. J Occup Rehabil. 2012;22:394-400.

https://www.ncbi.nlm.nih.gov/pmc/articles/PMC6205246/\# bib0095

8. Lee S, Lee SH, Choi WC, Choi G, Shin SW, Kaul R. Percutaneous endoscopic inter laminar discectomy for L5S1 disc herniation: axillary approach and preliminary results. J Korean Neurosurg Soc. 2006;40(2):79-83.

9. Choi KC, Kim JS, Ryu KS, Kang BU, Ahn Y, Lee SH. Percutaneous endoscopic lumbar discectomy for L5-S1 disc herniation: trans foraminal versus inter laminar approach. Pain Phys. 2013;16(6):547-556.

10. Li ZZ, Hou SX, Shang WL, Song KR, Zhao HL. The strategy and early clinical outcome of full-endoscopic L5/S1 discectomy through inter laminar approach. Clin Neurol Neurosurg. 2015;133:40-45.

11. Kyung-Chul Choi, MD, PhD, June-Ho Lee, MD, PhD, JinSung Kim, MD, PhD, et al. Unsuccessful Percutaneous Endoscopic Lumbar Discectomy: A Single-Center Experience of 10228 Cases, Neurosurgery, 2015 April;76(4):372-381.
12. https://doi.org/10.1227/NEU.0000000000000628. 